\title{
LA HISTORIOGRAFÍA ARTÍSTICA ANDALUZA EN LOS SIGLOS XVIII Y XIX
}

\author{
POR ANTONIO DE LA BANDA Y VARGAS
}

\begin{abstract}
Como avance de un trabajo de mayor alcance, en preparación, se ofrece aquí una síntesis de lo que ha sido el desarrollo de la Historiografía artística andaluza, entendiendo por tal la editada en suelo regional, durante los siglos XVIII y XIX. La misma abarca, desde el punto de vista ideológico y estético, un arco evolutivo que va desde tardobarroquismo dieciochesco hasta el positivismo y el eclecticismo propios de la segunda mitad del siglo XIX; apareciendo en su contexto obras del interés de los comentarios sobre Vignola del gaditano Tomás de Sisto,los trabajos de Ceán Bermúdez que vieron la luz en Andalucía, las obras de Tubino, Boutelou, Sentenach y, más en el final de la pasada centuria, las de Gestoso y Gómez Moreno "el Viejo" por citar sólo las más representativas.
\end{abstract}

As an advance notice of a far - rearching piece of Work, it is offered here a synthesis of what has been the development of the artistic andalusian historiography, considering as such, the one published during the 17th and 18th centuries. This one covers, from an aesthetic and ideological point of View, and evolutionary period which goes from the late baroque style of the 18th century to the positivism and eclecticism characteristic in the second half of the 19th century.

Quotine only the most representative books that appear in that context we have works of interest like the "Commentaries on Vignola" by Tomás de Sisto of Cadiz, the work of Cean Bermúdez which was published in Andalusia the books of Tubino, Bontelon, Sentenach and more at the end of the last century, those of Gestoso and Gómez Moreno "The Elder".

Como avanzadilla de un trabajo más extenso que tengo en preparación, ofrezco esta panorámica de la historiografía artística andaluza de las aludidas centurias, incluyendo en ella, pese a tener que dejar fuera títulos de la entidad y el interés del Tratado de Arquitectura del III Marqués de Ureña ${ }^{1}$ o del de Anatomía Artística del pintor Antonio María Esquivel ${ }^{2}$, sólo las obras que vieron la luz en el suelo regional

1. Vid. UREÑA (Marqués de) "Reflexiones sobre la arquitectura y ornato del templo". Madrid 1785.

2. Vid. ESQUIVEL Y SUAREZ DE URBINA (Antonio Maria). "Tratado de Anatomía Artística". Madrid 1848. 
sean de contenido estético, teórico o histórico, así como aquellas Guías monográficas de ciudades que, verdaderamente, tengan un matiz especializado de carácter histórico-artístico.

El arco evolutivo que, desde el punto de vista estilístico, abarcan las mismas va desde el tardobarroquismo dieciochesco hasta el realismo positivista de la segunda mitad del siglo XIX, pasando por el academicismo ilustrado, el neoclasicismo, el romanticismo y el historicismo por lo que su contenido doctrinal lo hace desde las libertades estéticas y las aún vigentes doctrinas escolásticas, propias del barroco hasta el aludido positivismo, más o menos contesiano, propio de la ciencia finidecimonónica, pasando por el idolátrico culto a la antigüedad clásica propio de academicistas y neoclásicos, el más o menos literaturalizable de los románticos y el arqueologismo propio de los historicistas.

Curiosamente, el tardobarroquismo setecentista fue poco prodigo en escritos de carácter artístico tanto doctrinales como puramente descriptivos, tal vez por la condición artesanal de la mayor parte de los artistas, tal vez, también, por el eco que en los medios artísticos andaluces tuvieron esas dos joyas de la historiografía artística nacional que son "El Arte y Uso de la Arquitectura" de Fray Lorenzo de San Nicolás ${ }^{3}$ y "El Museo Pictórico y Escala Optica" de Don Acisclo Antonio Palomino de Castro y Velasco 4 No obstante, hay alguna que otra muestra de la cual la más antigua es el opúsculo que recoge las consultas hechas al arquitecto Leonardo de Figueroa, la figura mas representativa del tardobarroquismo andaluz diciochesco, con motivo de la iniciación de las obras de la Catedral nueva de Cádiz, en las que por cierto dictaminó, entre otras cosas, el que no se elevase mucho la cúpula por la fuerza de los vientos allí reinantes, con el ampuloso- título "Extracto de los dictámenes dados por los maestros consultados sobre las dudas que se han ofrecido en cimientos, planos y alzados de la Iglesia Catedral que se está construyendo en Cádiz con que se informa a todos y satisfacen a los bienhechores, afectos y amigos de la verdad" 5 .

Su hijo y colaborador Matías José, también arquitecto y muy interesado por los problemas teórico-prácticos que plantea la construcción de cualquier edificio, es autor de dos interesantes publicaciones: una de carácter defensivo contra ciertos alegatos que le hicieron con motivo de la construcción del templo conventual trianero de San Jacinto, que lleva por título "Satisfacción que da al público Mathias José de Figueroa, Arquitecto Mayor de esta Ciudad de Sevilla sobre la casualidad de haber visitado de orden de la Ciudad unos maestros la obra nueva de la Iglesia de San Jacinto de religiosísimos Padres Domínicos de Triana en cuya obra estuvo como arquitecto algunos días" 6 , y la otra, mucho más interesante por su carácter doctrinal y por la defensa que hace de la arquitectura de albañilería, titulada "Pregunta que hace un Geographo a un Artífice Architetto, sobre si los edificios de

3. Madrid, 1736.

4. Tomo I: Madrid, Antonio de Bedmar, 1715; Tomo I: Madrid, Vda. de Juan García Infanzón, 1724, y Tomo III: Madrid 1724.

5. Impreso en Cádiz por Geronymo Peralta. :

6. Sevilla, 1771 . 
ladrillos son mas permanentes que los fabricados de piedra y si las barras de hierro son perjudiciales a las piedras o favorables en las fábricas de ladrillos" ?.

Y, prácticamente, nada más salvo una "Descripción breve del nuevo templo del Salvador de Sevilla" ${ }^{8}$, impresa en dicha ciudad el año 1712, que, aunque escrita en verso, contiene interesantes datos artísticos acerca de tan importante monumento barroco andaluz.

Tampoco hay mucho de la época del Academicismo ilustrado -reinados de Carlos III y Carlos IV- pese a ser este el momento de la creación de las Escuelas de Nobles Artes de Sevilla, Granada y Cádiz. En primer lugar, la "Carta apologética sobre el Noble Arte de la Arquitectura" ${ }^{19}$ del tudelano Lucas Cintora, Director de Arquitectura en el primero de los centros docentes aludidos, en la que, aparte de ciertas reflexiones técnicas sobre las obras de restauración que llevó a cabo en la Parroquia del Sagrario de la Catedral hispalense, ofrece un corto pero interesante cuerpo doctrinal de índole clasicista y por tanto claramente superador de la estética barroca.

Con la llegada del Neoclasicismo, vigente durante los últimos días carolinos y durante toda la etapa fernandina, Cádiz, la ciudad más progresista del sur de España y por tanto las mas proclive al ideario del nuevo estilo, adquirió un importante protagonismo en materia de publicaciones de índole artística gracias a los estudios del erudito militar Don Tomás de Sisto y Vaccaro, Secretario que fue de la gaditana Escuela de Nobles Artes y de la Real Sociedad Económica de Amigos del País de dicha capital ${ }^{10}$, que llevan por título "Principios de Arquitectura según el sistema de Vignola" ${ }^{11}$ y "Vistas de Cádiz" ${ }^{2}$.

La primera, de cuyo contenido hice una glosa hace ya veintiún años ${ }^{13}$, es un texto para el alumnado de la Escuela Local de Nobles Artes, publicado a sus expensas previo informe de sus docentes tectónicos, los arquitectos neoclásicos Pedro Angel Albizu y Torcuato José Benjumeda, en 1813 y que, aunque tiene un carácter elemental -"Los estrechos límites de este tratado elemental no permiten dar mayor extensión a las máximas expuestas en él, son sin duda las mas esenciales para evitar que los arquitectos contravengan los preceptos del arte y las leyes del buen gusto" ${ }^{14}$ - es ciertamente una verdadera profesión de fe en los principios de la arquitectura clásica y un manifiesto alentador de esa renovación del gusto artístico tan ansiada por nuestras Academias de Bellas Artes.

7. Sevilla, José Izquierdo, hacia 1755.

8. Sevilla, 1712.

9. Sevilla, 1771.

10. OROZCO ACUAVIVA (Antonio): "Los orígenes de la Academia de Bellas Artes de Cádiz y los artistas de su tiempo". Cádiz $1973 \mathrm{pg} .16$.

11. SISTO Y VACCARO (Tomás de): "Principios de arquitectura según el sistema de Vignola para uso de los alumnos de la Academia de Nobles Artes de Cádiz". Cádiz, Imprenta del Estado Mayor General. Año de 1813.

12. SISTO Y VACCARO (Tomás de): "Vistas de Cádiz". Cádiz 1812.

13. Vid. BANDA Y VARGAS (Antonio de la): "Un comentarista gaditano de Vignola" en "En torno a Pemán". Cádiz 1974 pgs. 201/208.

14. Vid. op. cit. en la nota $\mathrm{n}^{\circ} 11$ pg. 45. 
Reeditada por la Delegación gaditana del Colegio Oficial de Arquitectos de Andalucía Occidental en acertada tirada fascimilar ${ }^{15}$, consta, aparte de un prólogo y de un apartado referente a los acuerdos académicos relacionados con su publicación, de nueve capítulos y de un apéndice que contiene una introducción y dieciséis títulos, así como está ilustrada por treinta y cinco láminas debidas a los grabadores J. Ramos, P. Gascó, J. Bonifaz y V. Pascual, y aunque no es "el único tratado completo de arquitectura que existe en castellano", como afirma su autor ${ }^{16}$, si es un acertado vademecum para los estudiantes del momento y una pieza emblemática en la historiografía neoclásica española.

La segunda, también reeditada en tirada fascimilar por la Real Academia de Bellas Artes con un estudio introductorio que redacté por su encargo ${ }^{17}$ no es otra cosa que un precioso álbum de dibujos de los principales monumentos locales, especialmente los academicistas y neoclásicos de Torcuato Cayón de la Vega y del aludido Benjumeda, a los que acompañan unos comentarios escritos por su corto pero interesante texto, se trasluce la sincera devoción que, tanto la Escuela de Nobles Artes como Sisto, profesaban a la estética neoclásica y el claro repudio hacia la barroca, tan denostada por los tratadistas del momento, considerada como una auténtica aberración del gusto y por ello como algo a desterrar del panorama tectónico nacional.

Capítulo muy importante de la historiografía artística andaluza del momento son las obras del erudito Don Juan Agustín Ceán Bermúdez que vieron la luz en suelo regional. Son cinco en total: "La carta sobre el gusto y estilo de la pintura sevillana"18; "El diálogo sobre el arte de la pintura" 19; "La descripción del Hospital de la Sangre de Sevilla" ${ }^{20}$; "La descripción de la Catedral hispalense" ${ }^{21}$, y el estudio previo a la edición fascimil del libro de Juan de Arfe sobre la Custodia procesional de dicho templo metropolitano ${ }^{22}$.

La primera, cuyo título exacto es "Carta de Don Juan Agustín Ceán Bermúdez a un amigo suyo sobre el estilo y gusto de la escuela sevillana y sobre el grado de perfección a que la elevó Bartolomé Esteban Murillo, cuya vida se inserta y se describen sus obras en Sevilla", es la primera historia sobre la aludida escuela. pictórica y sobre todo la primera biografía del referido maestro. Está dedicada a su protector Don Gaspar Melchor de Jovellanos, al que llama "mi dulce y verdadero amigo", y contiene un somero recorrido, basado en datos documentales, por sus mas destacados representantes desde el tardogoticista Juan Sánchez de Castro hasta el

15. Reeditado por INGRASA. Cádiz 1988.

16. Vid. op. cit. en la nota $\mathrm{n}^{\circ} 11 \mathrm{pg} .2$.

17. Págs. $3 / 7$

18. Impresa en la Casa de la Misericordia de Cádiz en 1806.

19. Sevilla, Manuel de Aragón y Compañía. 1819.

20. 1804.

21. Sevilla, 1804.

22. GESTOSO Y PEREZ (José): "Introducción a la descipción de la Custodia de la Catedral hispalense. Sevilla 1893 
propio Murillo, con una evidente parcialidad -"Estoy seguro de que V.m. conociendo mi afecto, mi celo y algún otro exceso de mi fantasía, haciéndose cargo de que escribo en Andalucía, donde todo suspira al entusiasmo..." 23 - al par que concluyendo con la triste reflexión acerca del lamentable estado en que se encontraba en el momento en que escribe.

Dicha tristeza, al comparar su glorioso pasado con el mediocre panorama del momento academista de un Joaquín Cortés o de un Juan de Dios Fernández e incluso del neoclasicismo de un José María Arango, conduce al planteamiento de una sugestiva interrogación: ¿ Cómo es posible que un ilustrado de tan arraigadas convicciones clasicistas desdeñe la pintura de su tiempo, con su corrección dibujística, su destacada plasticidad y su notorio acromatismo, para ensalzar el colorismo y la dinamicidad barroca? La respuesta creo que no es otra, aparte su devoción murillesca, que el descubrir que la fiebre antibarroca de los ilustrados solo alcanzó. a la arquitectura, a la retablística y a la ornamentación, manteniendo, en cambio una actitud respetuosa hacia la plástica realista e incluso barroca, tal vez por su casi exclusivo matiz devocional, junto con una clara admiración por la pintura seiscentista y especialmente por Velázquez y Murillo.

Esta actitud minivalorizadora hacia la pintura clasicista la continua en la segunda de las obras mencionadas, que no es otra cosa que una idílica confrontación entre Murillo y Antón Raphael Mengs, nada menos que en el empireo, en la que ambos personajes dialogan sobre su formación y principios estéticos con resultado negativo, para el quehacer del bohemio, cuyos discípulos no arribaron a buen puerto a causa del cansancio que experimentaron ante la aburrida doctrina clasicista, frente al óptimo alcanzado por Murillo; llegando, incluso, a afirmar que el aludido credo clasicista dio al traste con la pintura en España.

La tercera y la cuarta son unas pequeñas pero excelentes monografías sobre los mencionados monumentos sevillanos, redactadas con una erudición documental fruto de una concienzuda labor de investigación en los archivos locales al par que con unos juicios estéticos nada desdeñables. Por último, la quinta es un estudio preliminar al testimonio del gran orfebre manierista sobre la construcción de la famosa custodia catedralicia hispalense, cuyo título exacto es: "Descripción de la traba y ornato de la Custodia de plata de la Santa Iglesia de Sevilla"; trío de obras que prueba, una vez más, su sorprendente erudición y sus delicados gustos.

Cierra el apartado referente a la historiografía artística andaluza del momento neoclásico, la conocida obra de Don Nicolás de la Cruz Bahamonde -"Viaje de España", impresa en Cádiz ${ }^{24}$ que, pese a no ser un libro propiamente históricoartístico, debe incluirse aquí por los numerosos datos que aporta sobre la materia.

Algo corta es la historiografía artística andaluza del período romántico y curiosamente casi toda ella está impresa en Cádiz. Abre el repertorio la sucinta pero

23. Vid. op. cit. en la nota $\mathrm{n}^{\circ} 18$ pgs. $133 / 134$.

24. 1813. 
muy interesante "Descripción histórico artística de la Catedral de Cádiz para que sirva de guía a los viajeros que visitan esta capital", debida al erudito local Don Javier de Urrutia ${ }^{25}$. Diez años después, vio la luz, también la ciudad de Hércules, el anónimo "Paseo histórico-artístico por Cádiz para que sirva de guía a los viajeros que visitan esta capital" ${ }^{26}$; obra de carácter más científico que propiamente turístico y con datos muy interesantes sobre su acervo monumental. También hay que citar el "Paseo artístico por Cádiz" de José Nicolás Enrile ${ }^{27}$, cuya lírica redacción acusa su acentuado romanticismo.

Hito singular en la historiografía artística andaluza es, si es que llegó a publicarse, es el "Tratado de Anatomía Artística" del pintor prerromántico gaditano Joaquín Manuel Fernández Cruzado y que, supongo, escribiría para el alumnado de la Escuela de Bellas Artes de Cádiz, de la que fue Catedrático y Director; obra esta, mencionada por su biógrafo Urrutia ${ }^{28}$ y por cuantos con posterioridad nos hemos ocupado de él ${ }^{29}$, que resulta un tanto fantasma pues ni se encuentra en ninguna biblioteca local ni en cuantas, regionales o no, he podido consultar, por lo que pienso si solo sería un manuscrito, conocido por Urrutia y citado en su aludida Necrología ${ }^{30}$, que nunca se editó y que, basándose en el referido erudito gaditano ${ }^{31}$, ha pasado a la posterior bibliografía sobre el pintor, sin que nadie, hasta ahora, se haya preocupado de comprobar la veracidad del aserto. Ocupado como estoy en la redacción de una monografía sobre dicho artista, espero poder aclarar, definitivamente, esta interrogante.

Otras publicaciones artísticas andaluzas del momento son: "Noticia artística de Sevilla" de Félix González de León ${ }^{32}$, obra de gran interés por los numerosos datos eruditos que ofrece y que se complementa con "Las calles de Sevilla" del mismo autor ${ }^{33}$, modelo, igualmente, de cumplida erudición. También hay que citar, dentro de este apartado, la "Sevilla Artística" de Juan Colom y Colom ${ }^{34}$ y la "Sevilla Pintoresca" de José Amador de los Ríos (35). Por último y aunque su contenido es puramente literario y nada erudito, mencionaré, por su acentuado romanticismo, la conocida "Guía del Alcázar de Sevilla" de Fernán Caballero ${ }^{35}$.

Muy interesantes son los trabajos del cordobés Luis Ramírez y de las CasasDeza, de carácter más literario que histórico artístico pero con importantes datos

25. Cádiz 1843.

26. Cádiz, 1853.

27. Cádiz, 1843.

28. Vid. URRUTIA (Javier de): "Biografía de Don Joaquín Marín Fernández". Cádiz, 1856.

29. Vid. AA.W.: "Estudios sobre el pintor Fernández Cruzado (1781/1846). Real Academia Provincial de Bellas Artes. Cádiz, 1983.

30. Vid. op. cit. en la nota $n^{\circ} 28$.

31. Vid. la nota anterior.

32. Sevilla, 1844.

33. Sevilla, 1839.

34. Sevilla, 1841.

35. Sevilla 1860. 
eruditos, el "Indicador cordobés" ${ }^{36}$ y los deliciosos "Paseos por Córdoba" ${ }^{37}$ que aunan lirismo romántico con altura científica pese a su ya comentado matiz altamente literario.

El comedio del siglo XIX supuso, prácticamente, la superación del idealismo romántico al que sustituyó el racionalismo positivista así como, desde el punto de vista estilístico, supuso la aparición de la estética historicista que, a su vez, fue superada por las diversas facetas del naturalismo, e incluso después por la arquitectura de los nuevos materiales y por las manifestaciones artísticas de índole impresionista o modernista. También, desde el punto de vista historiográfico, supuso la redacción de obras más científicas -no se olvide que es el momento del nacimiento de la Historia del Arte como ciencia- así como el aumento de estudiosos de la materia.

De ahí, pues, el notable aumento de las publicaciones artísticas andaluzas y la mayor profusión de datos que contienen los netamente históricos. Por ello, a la hora de analizarlos, conviene dividirlas en dos grandes apartados: los propiamente especializados en cualquier materia artística, tanto desde el punto de vista estético o teórico, y las guías de poblaciones con contenido científico.

Entre los primeros y más concretamente entre los puramente teóricos, hay que citar el "Manual de Estética y Teoría del Arte" del entonces Profesor de Retórica y Poética del Instituto gaditano Don Salvador Arpa y López, que luego fue docente del madrileño, cuya primera edición se hizo en Cádiz ${ }^{38}$ y luego fue objeto de una segunda en la Capital del Reino ${ }^{39}$. De clara intención docente, pues se escribió para el alumnado del Instituto Musical de Santa Cecilia de Cádiz, no es otra cosa que un sencillos textito en el que, con lenguaje claro y sencillo y a base de preguntas y respuestas, se doctrina al lector sobre los puntos más importantes de estética, teoría artística y literaria y musical al par que se enumeran los principales preceptos de dichas materias.

Igualmente cabe dentro de este apartado la obra de A. Cánovas Vallejo "El arte, el artista y el hombre" ${ }^{40}$, que es un auténtico tratado estético a nivel no escolar sino altamente culto. También hay que incluir el texto del Discurso pronunciado en la Academia de Bellas Artes de Sevilla por Don Claudio Boutelou Soldevilla en la inauguración del curso $1883 / 1884^{41}$; los también pronunciados en la gaditana por su Secretario Don Roque Yanguas Mesias ${ }^{42}$, por Don Francisco Flores Arenas ${ }^{43}$ y por Don Adolfo de Castro ${ }^{44}$ y por Don Juan José de Urmeneta ${ }^{45}$ así como, en la

\footnotetext{
36. Córdoba 1837.

37. Córdoba, 1838.

38. 1876.

39. 1895.

40. Málaga, 1896.

41. Sevilla, 1884.

42. Cádiz, 1884.

43. Cádiz, 1885.

44. Cádiz, 1862.

45. Cádiz, 1864.
} 
malagueña y con motivo del cuadragésimo aniversario de su fundación, por Don Benito Villa Comino ${ }^{46}$.

Mención especial merecen las obras del célebre médico gaditano Don Cayetano del Toro y Quatriell -"La luz en la pintura" ${ }^{47}$ y "El gusto estético"48 - ambas producto de su vasta erudición y bases para su famoso"Manual del artista-pintor" 49 , ya fuera de los límites cronológicos de este trabajo, que, según Orozco Acuaviva ${ }^{50}$ son "unos estudios filosóficos sobre Estética a la luz del idealismo y del naturalismo".

Entre los de carácter histórico-artístico propiamente dicho hay que destacar los del ya mencionado Boutelou, así como los de Narciso Sentenach y Cabañas. Los del primero - primer Catedrático de Historia del Arte que hubo en Andalucía, materia que explicó en la Escuela Sevillana de Bellas Artes ${ }^{51}$ - son, "La pintura en el siglo XIX"52 y " El arte cristiano en España" ${ }^{53}$. La primera de ellas es un interesante estudio sobre el devenir de la pintura española desde Goya al realismo vigente en el momento de su redacción, mientras que la segunda lo es de "La pintura en Sevilla" ${ }^{54}$, muy dentro de la línea investigadora de Ceán Bermúdez, que complementa con un apéndice en el que trata sobre las miniaturas y las vidrieras de la Catedral hispalense así como de la cerámica trianera al par que de unos "Estudios sobre cerámica sevillana" 55 , escritos en colaboración con José Gestoso y Pérez.

Este último merece, por lo abundante y selecto de su producción, un tratamiento especial. Conforme con ello, vaya, en primer lugar, el análisis de su "Ensayo de un Diccionario de los artífices que florecieron en Sevilla desde el siglo XIII al XVIII", en tres tomos ${ }^{56}$, producto de una concienzuda investigación en los archivos locales, con citas puntuales acerca de la procedencia documental de los datos que consigna. Le sigue "Sevilla Monumental y Artística", también en tres tomos ${ }^{57}$, modelo, en su época, de catálogo monumental y que, pese a su lógica superación temporal, aún es de obligada consulta para cuanto se relaciona con la Ciudad del Guadalquivir. Le sigue la interesante monografía "Pedro Millán, ensayo biográfico-crítico" ${ }^{58}$ en la que dio a conocer a este delicado escultor tardogoticista sevillano y, por último,

46. Málaga, 1891 .

47. Cádiz, 1894.

48. Cádiz, 1896.

49. Cádiz, 1906.

50. Vid. OROZCO ACUAVIVA (Antonio): "Cayetano del Toro Ateneista", en "Homenaje a Cayetano del Toro". Vol. VII de los "Anales de la Real Academia de Medicina de Cádiz". Año 1982, n² 2 pag. 127.

51. Vid. BANDA Y VARGAS (Antonio de la): "Noticias sobre la primera Cátedra sevillana de historia del arte" en el "Homenaje de la Universidad de Sevilla al Profesor Carriazo". Tomo II, Sevilla 1972, págs. 43/55.

52. Sevilla, 1877.

53. Sevilla, 1879.

54. Sevilla, 1885.

55. Sevilla, 1882.

56. Tomos I y II, Sevilla 1889 y Tomo III, Sevilla 1901.

57. Sevilla, 1889 a 1892.

58. Sevilla, 1884. 
el no menos sobre "Valdés Leal y Mañara" 59 es un avance al importante estudio que publicó dieciséis años después sobre este gran pintor barroco sevillano ${ }^{60}$.

Obras menores de este insigne erudito hispalense, insertas en la cronología de este estudio, son: "Guía del Alcázar de Sevilla" ${ }^{61}$; "Historia y descripción de la Sacristía Mayor de la Catedral de Sevilla y de las preciosidades artísticas que en ella se custodian" ${ }^{62}$; "El navío del San Rey Don Fernando" ${ }^{63}$, interesante estudio sobre la falúa, decorada por Zurbarán, que el Concejo hispalense regaló a Felipe IV, así como la "Noticia histórico descriptiva del antiguo pendón de la ciudad de Sevilla" ${ }^{4}$, donde analiza esta interesante pieza de bordado medieval que se conserva en el tesoro de la catedral hispalense.

El gaditano Francisco María Tubino, tan polifacético de actividades pues fue escritor, pintor y político de la mas radical ideología progresista, es autor de dos importantes libros de contenido histórico-artístico: "Murillo, su época, su vida y sus cuadros" $^{65}$ y "Estudios sobre el arte en España"66. El primero, como su título indica, es una cuidada monografía, más crítica que erudita, sobre el célebre pintor seiscentista sevillano mientras que el segundo no es otra cosa que un compendio de artículos sobre diversas cuestiones relacionadas con el arte nacional.

El ya mencionado Adolfo de Castro, más historiador que crítico de arte aunque aporte muchos datos artísticos en su conocida "Historia de Cádiz" ${ }^{67}$, es autor de una curiosa "Carta al Ilmo. Sr. Obispo de Cádiz con motivo de la consagración del tabernáculo de la Santa Iglesia Catedral en 1866" ${ }^{68}$ que no es otra cosa que un razonado análisis crítico de esta presa catedralicia gaditana tardoneoclásica, construida por voluntad de Isabel II.

Por último, los trabajos del presbítero sevillano Don Manuel Serrano Ortega, tan controvertidos por Gestoso ${ }^{69}$, entre los que citaré el titulado "La imagen de Jesús del Gran Poder", pues los restantes ${ }^{70}$ caen fuera del límite cronológico de esta panorámica y, a su lado, la "Sevilla Mariana" de Alonso Morgado ${ }^{71}$, verdadero centón de datos artísticos sobre las imágenes marianas medievales de mayor devoción en la Archidiócesis hispalense. También cabe citar, dentro de este apartado, el "Catálogo

59. Sevilla, 1890.

60. Sevilla, 1906.

61. Sevilla, 1899.

62. Sevilla, 1885.

63. Sevilla, 1890.

64. Sevilla, 1887.

65. Sevilla, 1864.

66. Sevilla, 1866.

67. Cádiz, 1882.

68. Cádiz 1866.

69. Vid. GESTOSO Y PEREZ (José):

70. Sevilla, 1898.

71. Sevilla, 1881. 
de algunas de las antiguiedades reunidas por los Marqueses de Casa Loring en su Hacienda de la Concepción" 72 del erudito malagueño Juan Bautista Pernán.

Pasando al capítulo de las guías, mencionaré, en primer lugar, el "Manual del viajero en Cádiz" de Adolfo de Castro ${ }^{73}$ por lo que tiene de acabado estudio del conjunto monumental de dicha ciudad. A su lado "El cicerone de Sevilla" ${ }^{74} \mathrm{de}$ Joaquín Guichot y Sierra, también acabado estudio de los monumentos hispalenses, así como la "Guía de Sevilla" ${ }^{75}$ del mencionado Gestoso en la que resume el contenido de la "Sevilla Monumental y Artística".

También son curiosas, aunque de menor alcance científico, las malagueñas de Benito Vila ${ }^{76}$ y Antonio Mercier y Emilio de la Cruz ${ }^{77}$ que abarcan, también el ámbito de la provincia. Por último y en lugar de honor, la verdaderamente ejemplar "Guía de Granada" 78 de Don Manuel Gómez Moreno "el Viejo", cuya metodología, revolucionaria en su tiempo, sirvió de base a todos los posteriores estudios históricoartísticos relacionados con la Ciudad de los Carmenes, aparte la entidad altamente literaria de su atrayente texto.

Finalmente y a modo de epílogo, mencionaré algunas de las publicaciones relacionadas con las exposiciones artísticas andaluzas del momento. Son estas: el "Catálogo de las obras que forman la exposición retrospectiva de la pintura sevillana" 79 , redactado por Gestoso; el anónimo de los "Objetos expuestos en la Exposición Regional de Cádiz, celebrada por la Sociedad Económica de Amigos del País" ${ }^{80}$; la curiosa obra de Juan José Relosillas "Carta a un clubman o juicio crítico de las obras de arte ejecutadas en el Liceo de Málaga" ${ }^{81}$ y la aun mas curiosa "Noticia sobre el álbum que la Academia Provincial de Bellas Artes de Málaga ofreció en su día a Su Santidad León XIII con motivo de su jubileo sacerdotal y que, expuesto en la Exposición Vaticana, obtuvo Medalla de Oro" ${ }^{82}$.

\footnotetext{
72. Málaga, 1889.

73. Cádiz, 1870 .

74. Sevilla, 1896.

75. Sevilla, 1897.

76. Málaga, 1861.

77. Málaga, 1885.

78. Málaga, 1892.

79. Sevilla, 1896.

80. Cádiz, 1879.

81. Málaga, 1886.

82. Málaga, 1889.
} 